\title{
Komunitas Makrofauna Tanah pada Lahan Bekas TPA Gunung Tugel Kabupaten Banyumas
}

\author{
Soil Macrofauna Community in the Ex-TPA Gunung Tugel Land, Banyumas \\ Regency
}

\author{
Susanto $^{1^{*}}$, Astriana Putri Rahayu ${ }^{2}$ \\ ${ }^{1,2}$ Prodi Pendidikan Biologi FKIP Universitas Muhammadiyah Purwokerto \\ *corr-author: susanto280266@gmail.com
}

\begin{abstract}
ABSTRAK
Penelitian ini bertujuan untuk mengetahui dan mengungkap komunitas makrofauna tanah yang meliputi cacah individu, keanekaragaman dan dominansi serta kualitas lingkungan tanah di lahan eks TPA Gunung Tugel Desa Kedung Randu Kecamatan Patikraja Kabupaten Banyumas. Metode yang digunakan adalah purposive random sampling. Pengambilan sampel dilakukan selama enam bulan yaitu bulan Januari-Juni 2021 sebanyak enam kali dengan interval waktu selama satu bulan yaitu waktu siang hari (pukul 06.00 08.00) dan malam hari (pukul 18.00-20.00). Pengambilan sampel tanah dan pengukuran kualitas tanah dilakukan di dua lokasi penelitian, yaitu lokasi I di area sebelah utara dan timur lahan eks TPA Gunung Tugel dan lokasi II di area sebelah barat dan selatan lahan eks TPA Gunung Tugel. Hasil sampling diidentifikasi menggunakan mikroskop dan mengacu pada buku An Introduction to the Study of Insect dan buku Ekologi Hewan Tanah. Hasil penelitian menunjukkan cacah individu makrofauna tanah diperoleh sebanyak 1612 ekor yang termasuk kedalam 16 spesies, 13 Famili, dan 8 Ordo. Indeks keanekaragaman makrofauna tanah tergolong sedang yaitu kisaran 1,006 - 1,098 dengan rata-rata sebesar 1,066. Indeks dominansi makrofauna tanah pada lahan eks TPA Gunung Tugel tergolong kedalam kategori rendah dengan nilai kisaran antara 0,334-0,489 dengan rata-rata 0,374.
\end{abstract}

\section{Kata-kata kunci: Fauna tanah, cacah individu, keanekaragaman, dominansi, lahan} eks TPA Gunung Tugel.

\begin{abstract}
This study aims to identify and reveal the soil macrofauna community which includes individual count, diversity, and dominance as well as the quality of the soil environment in the former TPA Gunung Tugel land, Kedung Randu Village, Patikraja District, Banyumas Regency. The method used is purposive random sampling. Sampling was carried out for six months, namely January-June 2021, six times with an interval of one month, namely during the day (06.00 - 08.00) and at night (18.00-20.00). Soil sampling and soil quality measurements were carried out at two research locations, namely location I in the northern and eastern areas of the ex-TPA Gunung Tugel area and location II in the western and southern areas of the ex-TPA Gunung Tugel area. The results of the sampling were identified using a microscope and referred to the book An Introduction to the Study of Insects and the book Ecology of Soil Animals. The results showed that there were 1612 individual soil macrofauna counts, which belonged to 16 species, 13 families, and 8 orders.
\end{abstract}


Soil macrofauna diversity index was classified as moderate, in the range of $1.006-1.098$ with an average of 1.066. Soil macrofauna dominance index on the ex-TPA Gunung Tugel land belongs to the low category with a range value between $0.334-0.489$ with an average of 0.374 .

Keywords : diversity, dominance, former TPA, individual count, Gunung Tugel, Soil fauna

\section{PENDAHULUAN}

Fauna tanah dalam perannya terhadap ekosistem tanah dianggap sebagai salah satu indikator kesuburan dan kualitas tanah. Sebagai indikator dari kesuburan dan kualitas tanah, dengan adanya kemelimpahan serta keanekaragaman fauna tanah yang terdapat pada suatu wilayah dapat menjadi tolak ukur bagi kualitas tanah dan kondisi ekosistem tanah. Menurut Yan dkk. (2011), fauna tanah merupakan indikator yang sangat berguna bagi kualitas tanah karena fauna tanah sensitif terhadap perubahan yang ada di tanah dan termasuk dalam banyak fungsi tanah. Fauna tanah sebagai indikator dari kualitas tanah sangat bergantung terhadap faktor yang ada pada lingkungan tanah, meliputi faktor biotik dan abiotik tanah. Fauna tanah berperan melakukan proses dekomposisi dengan cara meluruhkan tumbuhan dan sisa-sisa organisme yang telah mati untuk diurai menjadi bahan organik sederhana dan kompleks. Bahan organik hasil dekomposisi inilah yang dapat menunjang produktivitas serta menjaga kesuburan tanah (Meitiyani dan Dharma, 2018).

Lahan bekas TPA Gunung Tugel berlokasi di Desa Kedung Randu, Kecamatan Patikraja, Kabupaten Banyumas. Lahan bekas TPA Gunung Tugel didirikan pada tahun 1983 dengan luas lahan sekitar 5 hektar. Lahan bekas TPA Gunung Tugel mampu menampung sampah anorganik maupun organik sebanyak $282 \mathrm{~m}^{2}$ per hari yang sebagian besar berasal dari rumah tangga, pasar, dan industri. Karena telah melebihi kapasitasnya, lahan ini ditutup pada tahun 2016 (Ramadhanti, 2018).

Fauna tanah merupakan dekomposer serta ecosystem engineer (pemelihara struktur tanah) berperan sangat penting terhadap kelangsungan ekosistem tanah. Terjaganya kelangsungan ekosistem tanah berpengaruh terhadap kelangsungan hidup organisme lain, misalnya tumbuhan. Fauna tanah juga memegang peranan penting dalam rehabilitasi tanah tercemar, contohnya rehabilitasi tanah lahan bekas TPA Gunung Tugel. Proses rehabilitasi tanah oleh fauna tanah melalui proses dekomposisi, imobilisasi, dan humufikasi tanah. Saat ini belum adanya penelitian tentang komunitas mesofauna dan makrofauna tanah yang terdapat pada lahan bekas TPA Gunung Tugel menjadi alasan utama tujuan penelitian ini. Mengingat proses rehabilitasi tanah di lahan bekas TPA Gunung Tugel, oleh karena itu diperlukan identifikasi mesofauna dan makrofauna tanah yang berperan penting dalam proses rehabilitasi tanah. Penelitian ini bertujuan untuk mengetahui dan mengungkap Struktur komunitas fauna tanah di lahan bekas TPA Gunung Tugel, hubungan antara faktor lingkungan terhadap cacah individu keanekaragaman dominansi fauna tanah di lahan bekas TPA Gunung Tugel (Amelinda, et al., 2017).

\section{METODE PENELITIAN}

Penelitian ini dilakukan di lahan bekas TPA Gunung Tugel, Desa Kedung Randu, Kecamatan Patikraja, Kabupaten Banyumas. Lahan ini memiliki luas sekitar 5 hektar. Penelitian ini dilakukan pada dua lokasi yang berbeda yaitu : Lokasi penelitian satu di lahan bekas TPA Gunung Tugel yang berlokasi di Desa Kedung Randu, Kecamatan Patikraja, Kabupaten Banyumas. Penelitian ini dilaksanakan selama enam bulan yaitu dimulai pada 
Januari 2021 sampai dengan Juni 2021. Penentuan waktu didasarkan pada perkiraan waktu efektif untuk melaksanakan penelitian dengan pertimbangan musim hujan dan musim kemarau. Pengambilan sampel dilakukan sebanyak enam kali dengan interval waktu selama satu bulan. Pengambilan sampel tanah dan sampel fauna tanah dilakukan pada pagi hari (pukul 06.00 - $09.00 \mathrm{WIB}$ ) dan sore hari $(18.00-21.00 \mathrm{WIB})$.

Pengambilan sampel fauna tanah yang dilakukan dalam penelitian menggunakan dua metode, meliputi metode pit fall trap dan metode tullgren funnel. Sampel makrofauna tanah diambil menggunakan metode pit fall traps, metode ini dilakukan dengan cara memasang perangkap berupa beaker glass atau botol plastik yang diisi dengan formalin $4 \%$, detergen, ethyl alkohol atau ethanol, etilen glikol, triisodium fosfat $\left(\mathrm{Na}_{3} \mathrm{PO}_{4}\right)$ yang kemudian ditambahkan aquades kedalamnya dengan ketinggian kurang lebih $1 / 2$ dari tinggi gelas atau yang lebih.

Pengukuran faktor lingkungan dilakukan pada masing-masing lokasi penelitian. Faktor lingkungan yang diambil data nya adalah : suhu udara, suhu tanah, $\mathrm{pH}$ tanah dan tekstur tanah. Pengukuran parameter lingkungan dilakukan pada pagi hari (pukul $06.00-$ 09.00 WIB).

Identifikasi dan Kuantifikasi Fauna Tanah. Proses identifikasi dan kuantifikasi sampel mesofauna dan makrofauna tanah dilakukan di Laboratorium Zoologi, Program Studi Pendidikan Biologi, Fakultas Keguruan dan Ilmu Pendidikan, Universitas Muhammadiyah Purwokerto.

Analisis data Keragaman dianalisis dengan nilai indeks keanekaragaman makrofauna ditentukan menggunakan Indeks Keanekaragaman Shannon-Wiener. Data dominansi dianalisis dengan Odum (1993), indeks dominansi suatu jenis tertentu dapat dihitung menggunakan Indeks Dominansi Simpson dengan persamaan sebagai berikut:

\section{HASIL DAN PEMBAHASAN}

\section{Struktur Komunitas Makrofauna Tanah}

Penelitian dimulai pada bulan Januari hingga Juni 2021 terbagi kedalam dua musim penelitian, yaitu musim hujan (bulan Januari hingga Juni 2021) dan musim kemarau (bulan April hingga Juni 2021). Cacah individu makrofauna tanah yang diperoleh dari lahan eks TPA Gunung Tugel selama bulan Januari hingga Juni 2021 sejumlah 1612 ekor dan setelah diidentifikasi terdiri atas 16 Spesies yang termasuk dalam 13 Famili dan 8 Ordo. Makrofauna tanah yang didapatkan pada penelitian merupakan anggota dari Ordo: Araneae (Famili: Agelenideae dan Philodromideae), Blattodeae (Famili: Ectobiideae), Coleoptera (Famili: Staphylideae), Diptera (Famili: Droshopilideae, Micropezideae, dan Culicideae), Hymenoptera (Famili: Formicideae), Orthoptera (Famili: Acridideae dan Gryllideae), Spirobolida (Famili: Spirobolodeae), Stylommatophora (Famili: Helicideae dan Agriolimacideae) disajikan pada Gambar 1. 


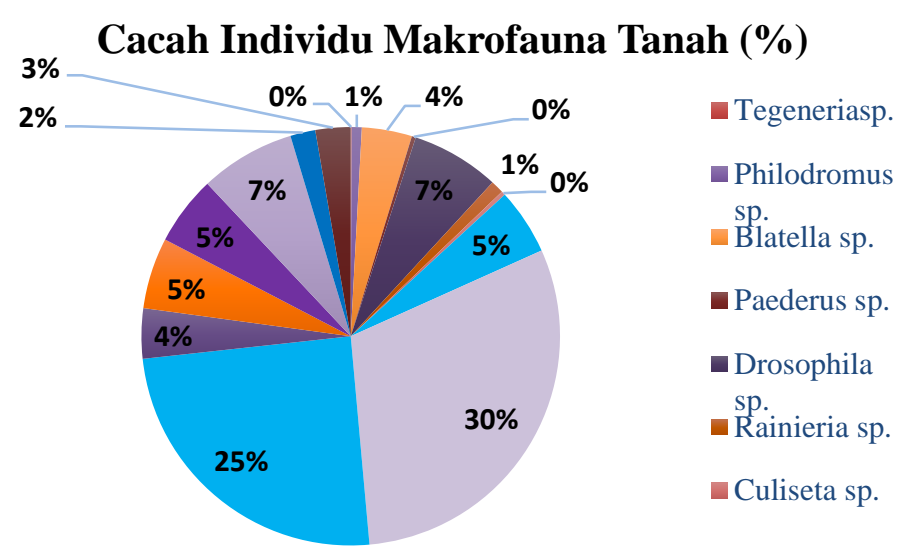

(A)

\section{Cacah Individu Makrofauna Tanah (\%)}

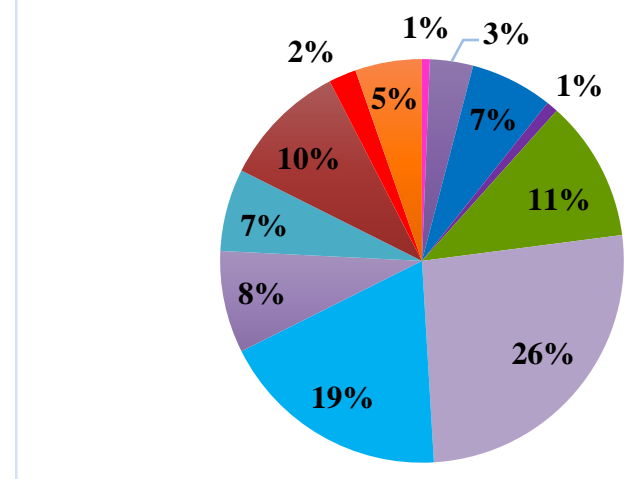

- Philodromus sp.

- Blatella sp.

- Drosophila sp.

- Rainieria sp.

- Camponotus

Solenopsis sp.

- Dolichoderus sp.

- Chrysochraon sp.

- Gryllodes sp.

(B)

Gambar 1. Cacah individu makrofauna tanah yang berhasil ditangkap berdasarkan tingkat Spesies dalam (\%) pada musim hujan (A) dan musim kemarau (B)

Cacah individu yang didapatkan dalam penelitian ini lebih sedikit apabila dibandingkan dengan hasil penelitian yang dilakukan oleh Utami dan Jannah (2014) di TPA Klotok Kota Kediri yang berhasil mendapatkan total cacah individu sejumlah 6.244 ekor. Menurut Nurrohman dkk. (2018) kemelimpahan cacah individu fauna tanah dapat disebabkan oleh beberapa faktor diantaranya tumbuhan penutup, kondisi dari tanah, dan kandungan bahan organik yang ada pada tanah. Rendahnya cacah individu yang berhasil ditangkap pada lahan eks TPA Gunung Tugel diduga dipengaruhi oleh kondisi lingkungan yang belum mendukung untuk kehidupan fauna tanah. Ramadhanti (2018) menyatakan bahwa lahan eks TPA Gunung Tugel ditutup pada tahun 2016 dan proses rehabilitasi tanah yang dilakukan oleh Dinas Lingkungan Hidup (DLH) Kabupaten Banyumas dilakukan pada tahun 2020. Hal ini tentu saja menginformasikan bahwa lahan eks TPA Gunung Tugel memerlukan waktu yang lebih lama lagi agar menjadi lingkungan yang tepat untuk kehidupan makrofauna tanah (At-Tawaha, dkk. 2021).

Nilai Indeks keanekaragaman makrofauna tanah pada lahan eks TPA Gunung Tugel pada waktu musim hujan dan kemarau berkisar antara 1,006 - 1,098 dengan rata-rata keseluruhan yaitu 1.066. Hasil analisis indeks keanekaragaman makrofauna tanah selama 
penelitian pada lahan eks TPA Gunung Tugel berdasarkan waktu pengambilan sampel memiliki nilai kisaran 2,009-2,230 pada waktu pengambilan sampel di siang hari dan nilai kisaran 2,035 - 2,276 pada waktu pengambilan sampel di malam hari dengan nilai rata-rata keseluruhan sebesar 2,160 sesuai dengan Gambar 2.

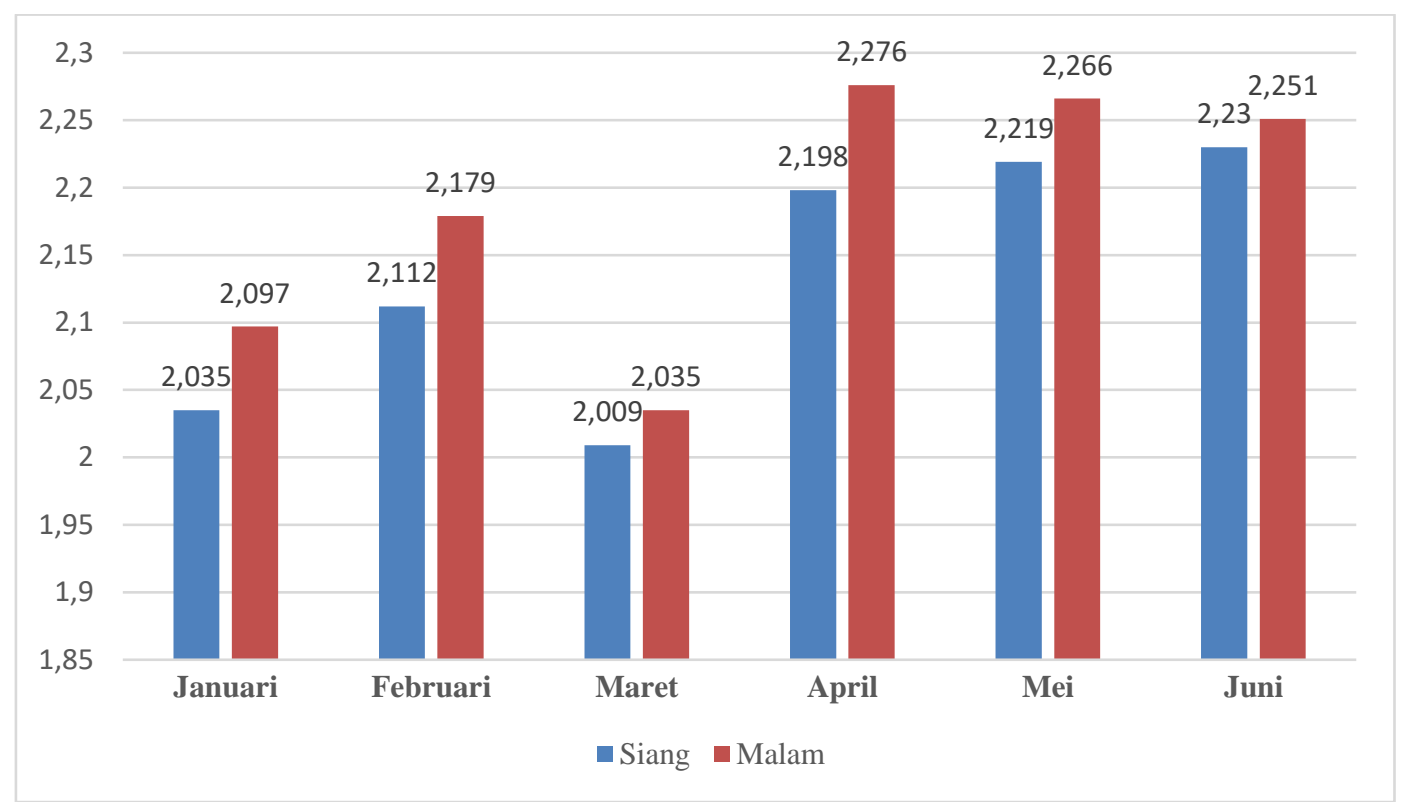

(A)

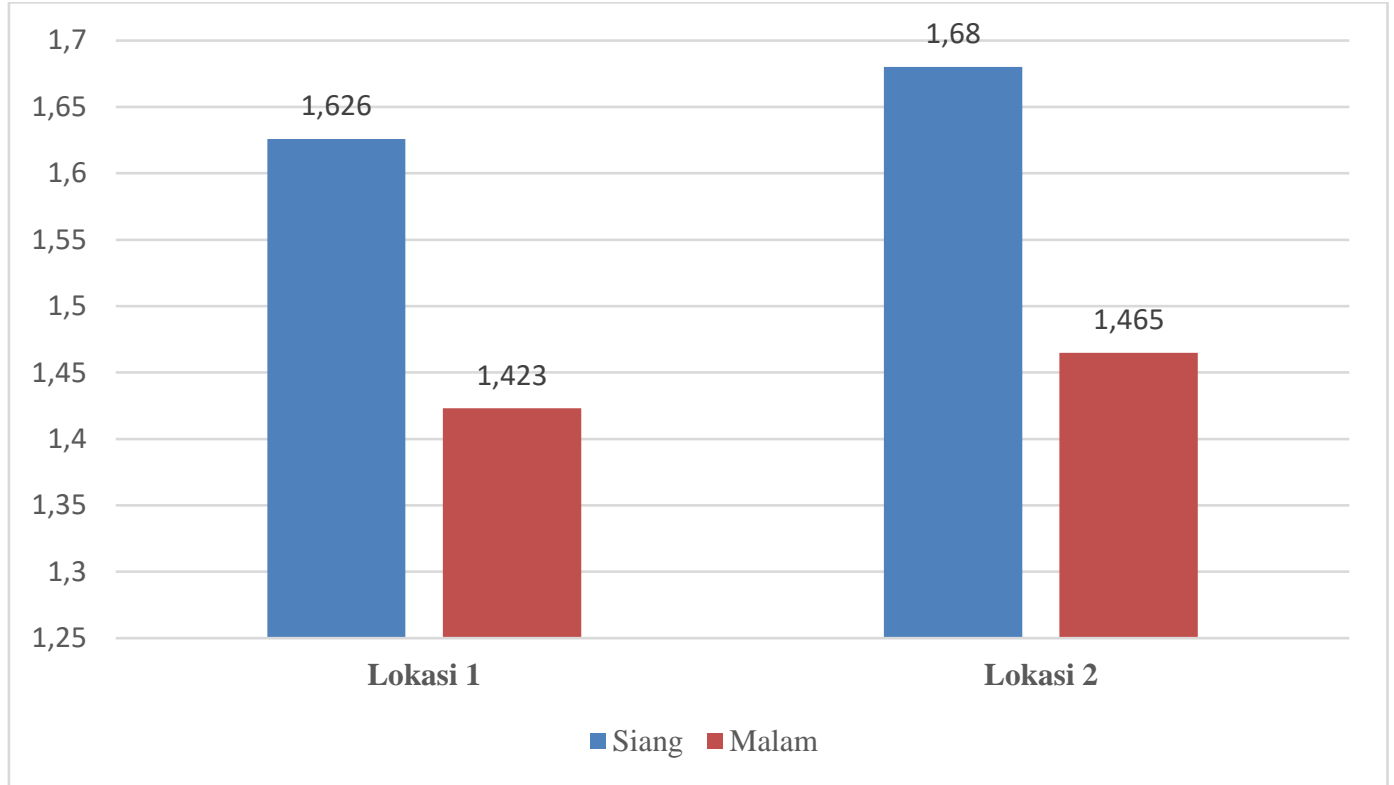

(B)

Gambar 2. Gambar Indeks keanekaragaman (H') makrofauna tanah berdasarkan waktu pengambilan sampel (A) dan berdasarkan lokasi penelitian selama penelitian $(B)$

Nilai indeks keanekaragaman yang diperoleh pada penelitian ini memiliki kriteria sedang dan sama dengan hasil penelitian yang dilakukan oleh Utami dan Jannah (2014) di 
TPA Klotok Kota Kediri yang berhasil mendapatkan nilai indeks keanekaragaman hayati kategori sedang. Nilai kategori sedang yang didapatkan pada penelitian makrofauna tanah di TPA Klotok disebabkan adanya salah satu spesies yang dominan pada lokasi penelitian tersebut (Harahap, dkk. 2016).

Nilai indeks dominansi (D) makrofauna tanah pada lahan eks TPA Gunung Tugel pada waktu musim hujan dan kemarau berkisar antara 0,334 - 0,489 dengan rata-rata keseluruhan yaitu 0,374. Hasil analisis indeks dominansi makrofauna tanah selama penelitian pada lahan eks TPA Gunung Tugel berdasarkan waktu pengambilan sampel memiliki nilai kisaran $0,115-0,462$ pada waktu pengambilan sampel di siang hari dan nilai kisaran $0,108-0,153$ pada waktu pengambilan sampel di malam hari dengan nilai rata-rata keseluruhan sebesar 0,216. Hasil analisis indeks dominansi makrofauna tanah selama penelitian berdasarkan lokasi pengambilan sampel mendapatkan nilai berkisar antara 0,208 - 0,282 dengan nilai rata-rata keseluruhan sebesar 0,248 data disajikan pada Gambar 3 . Berdasarkan perhitungan tersebut pada masing-masing musim baik musim hujan maupun kemarau, berdasarkan waktu pengambilan sampe, dan berdasarkan lokasi penelitian didapatkan hasil yang memiliki tingkat dominansi yang rendah karena nilai indeks tidak ada yang melebihi skala 0,5. Menurut Odum $(1993,1996,1998)$ jika $\mathrm{D}<0,5$ maka termasuk dominansi rendah.

\section{Faktor Lingkungan}

Hasil analisis pengukuran faktor lingkungan pada laahn eks TPA Gunung Tugel meliputi suhu udara, suhu tanah, derajat keasaman atau $\mathrm{pH}$ tanah, kelembaban tanah, dan tekstur tanah berkisar antara $26-32^{\circ} \mathrm{C}$. Hasil analisis pengukuran suhu tanah pada lahan eks TPA Gunung Tugel pada waktu musim hujan berkisar antara $29-33{ }^{\circ} \mathrm{C}$. Derajat Keasaman atau $\mathrm{pH}$ Tanah hasil analisis pengukuran derajat keasaman atau $\mathrm{pH}$ tanah pada lahan eks TPA Gunung Tugel berkisar 6 - 6,14. Kelembaban Tanah hasil analisis pengukuran kelembaban tanah pada lahan eks TPA Gunung Tugel berkisar antara 10 10,09\%. Tekstur Tanah hasil analisis tekstur tanah di lapangan secara manual serta menggunakan segitiga tekstur tanah didapatkan hasil yaitu Lokasi 1 memiliki tekstur liat berpasir (sandy-clay) dengan komposisi 50\% liat dan 50\% pasir. Lokasi 2 memiliki tekstur tanah lempung berpasir (sandy-loam) dengan komposisi $80 \%$ pasir dan $20 \%$ liat.

Hasil pengukuran faktor lingkungan yang dilakukan pada lahan eks TPA Gunung Tugel meliputi suhu udara, suhu tanah, derajat keasaman atau pH tanah, kelembaban, serta tekstur tanah didapatkan hasil bahwa lahan eks TPA Gunung Tugel belum memiliki kualitas lingkungan optimum yang cocok untuk mendukung kehidupan makrofauna fauna tanah. Hal ini disebabkan karena suhu udara yang cukup tinggi dan suhu tanah yang lebih tinggi dibanding suhu tanah optimum untuk kehidupan fauna tanah. Lingkungan tanah pada lahan eks TPA Gunung Tugel memiliki sifat asam sehingga kurang tepat sebagai habitat fauna tanah yang cenderung memilih hidup pada lingkungan denganpH mendekati netral. Kelembaban tanah pada lokasi penelitian yang memiliki kadar air rendah serta tekstur tanah yang didominasi oleh pasir menyebabkan kandungan air dalam tanah cenderung rendah sehingga bukan merupakan lingkungan yang ideal bagi fauna tanah dan dapat menyebabkan peluang kelangsungan hidup fauna tanah (Mafti'ah dkk. 2018; Nasirudin dan Susanti, 2018). 


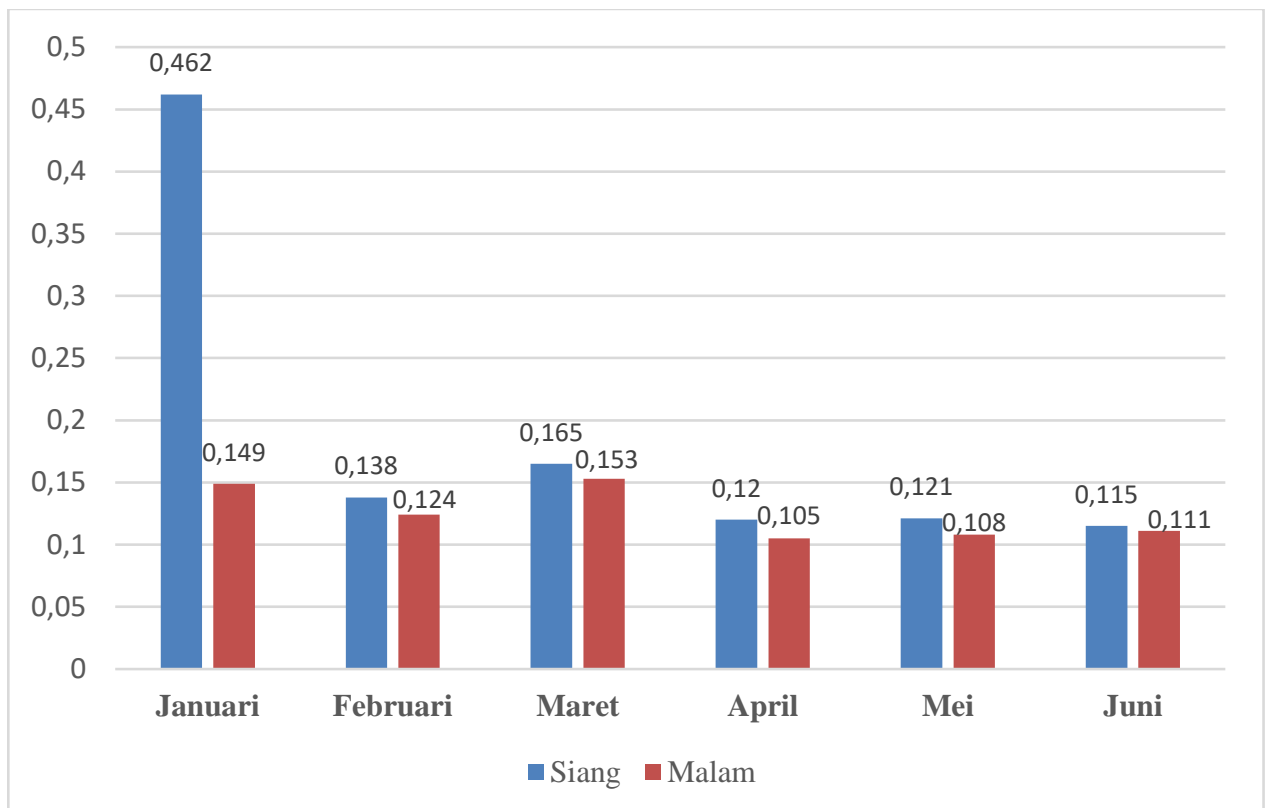

(A)

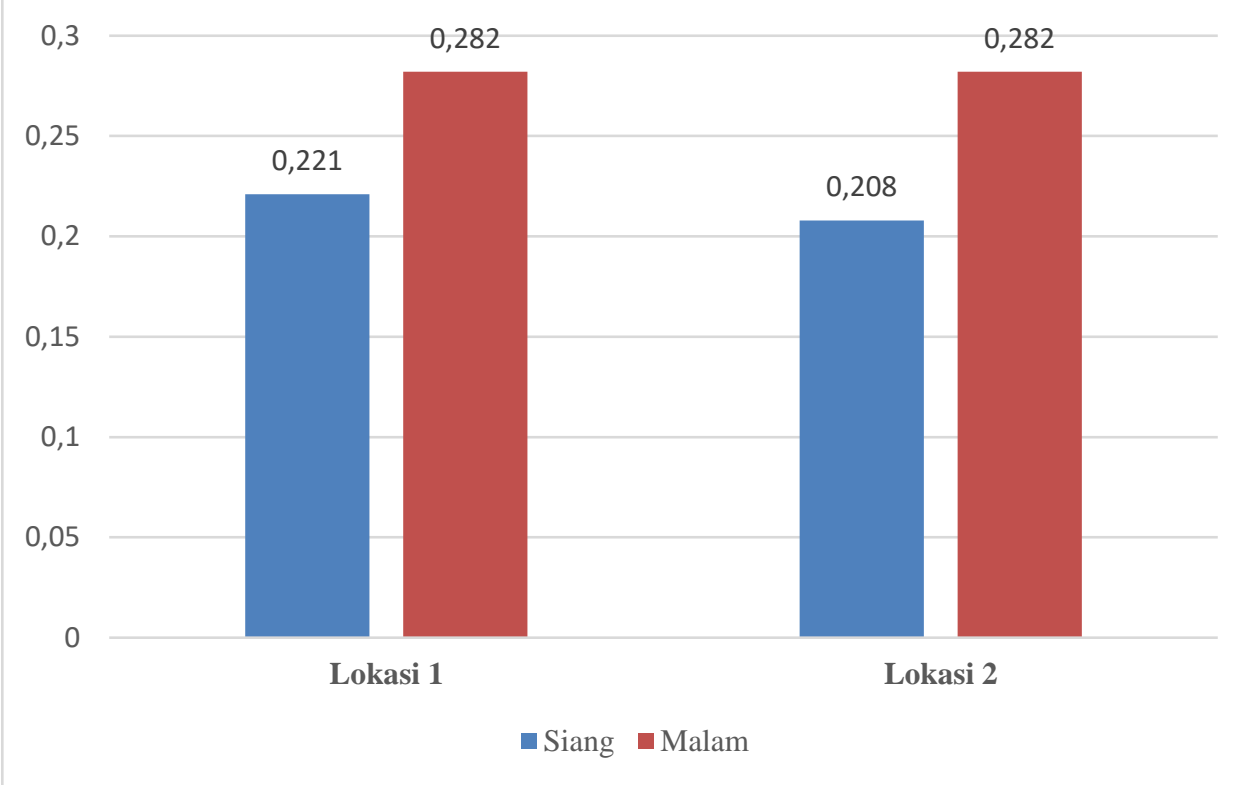

(B)

Gambar 3. Gambar Indeks dominansi (D) makrofauna tanah berdasarkan waktu pengambilan sampel (A) dan berdasarkan lokasi penelitian selama penelitian (B)

\section{KESIMPULAN}

Berdasrkan hasil dan pembahasan maka dapat disimpulkan bahwa Struktur komunitas makrofauna tanah pada lahan eks TPA Gunung Tugel Cacah individu makrofauna tanah pada lahan eks TPA Gunung Tugel berjumlah 1612 ekor yang terdiri atas 16 spesies, 13 famili, dan 8 ordo. Indeks keanekaragaman dan dominansi pada lahan eks TPA Gunung Tugel memiliki struktur komunitas yang tidak baik. Kualitas lingkungan tanah pada lahan eks TPA Gunung Tugel belum memiliki kualitas lingkungan optimum yang cocok untuk mendukung kehidupan makrofauna tanah. 


\section{DAFTAR PUSTAKA}

Amelinda, E.D., R. Rahardian, dan M. Hadi. (2017). Perbandingan Struktur Komunitas Mikroartropoda Tanah di Lahan Zona Aktif dan Pasif TPA Jatibarang Semarang. Jurnal Bioma, 2 (19): 141-149

At-Tawaha, A.R., S.K. Ahmad, H. Naz, dan A. At-Tawaha. (2021). Climate Change and Plants Biodiversity, Growth, and Interaction: Impact of Climate Change on Biodiversity of Insect Pest. CRC Press Taylor \& Francis Group. Boca Raton.

Harahap, A.I.P., Utomo, M., Yusnaini, S., Arif, S. (2016). Pengaruh Sistem Olah Tanah dan Pemupukan Nitrogen Terhadap Keanekaragaman dan Populasi Mesofauna Pada Serasah Tanaman Padi Gogo (Oryza sativa L.) Musim Tanam Ke-46. Jurnal Agrotek Tropika, 1(4) : 86-92.

Mafti'ah, Eni., M. Alwi, dan M. Willis. (2018). Potensi Makrofauna Tanah sebagai Bioindikator Kualitas Tanah Gambut. Bioscientiae, 2(1): 1-14.

Meitiyani dan Dharma, A.P. (2018). Diversity of Soil Arthropods in Different Soil Stratification Layers, The National Park of Gede Pangrango Mountain, Cisarua Resort, West Java, Indonesia. IOP Conference Series: Earth and Enviromental Science. Sci. 197012019.

Nasirudin, M. dan Susanti, A. (2018). Hubungan Kandungan Kimia Tanah Terhadap Keanekaragaman Makrofauna Tanah pada Perkebunan Apel Semi Organik dan Anorganik. Edubiotik. 3(2): 5-11.

Nurrohman, E., A. Rahardjanto, dan S. Wahyuni. (2018). Studi Hubungan Keanekaragaman Makrofauna Tanah dengan Kandungan C-Organik dan Organophospat Tanah di Perkebunan Cokelat (Theobroma cacao L.) Kalibaru Banyuwangi. Bioeksperimen. 4 (1): 1 - 10.

Odum, E. P. 1993. Dasar-dasar Ekologi Edisi Ketiga. Terjemahan oleh: T. Samingan dan Srigandono. Universitas Gajah Mada Yogyakarta.Yogyakarta.

Odum, E. P. (1996). Dasar-dasar Ekologi Edisi Ketiga. Terjemahan oleh: T. Samingan dan Srigandono. Universitas Gajah Mada Yogyakarta.Yogyakarta.

Odum, E. P. (1998). Dasar-dasar Ekologi Edisi Ketiga. Terjemahan oleh: T. Samingan dan Srigandono. Universitas Gajah Mada Yogyakarta.Yogyakarta.

Ramadhanti, S.A. (2018). Analisis Kandungan Zat Pencemar Dalam Air Lindi Serta Potensi Penyebarannya di TPA Gunung Tugel Banyumas. Skripsi. Fakultas Teknik. Universitas Islam Indonesia. Yogyakarta.

Utami, B. Dan S.N. Jannah. (2014). Identifikasi Makrofauna Tanah di Zona Pasif Tempat Pembuangan Akhir Klotok Kota Kediri. Biologi, Sains, Lingkungan, dan Pembelajaran. Seminar Nasional XI Pendidikan Biologi FKIP UNS: 780-785

Yan, S., Singh, A. N., Fu, S., Liao, C., Wang, S., Li, Y., Cui, Y dan Hu, L., (2011). A Soil Fauna Index for Assesing Soil Quality. Soil Biology and Biochemistry, 47:1-8. 